\title{
Renal dysfunction is an independent risk factor for bleeding after gastric ESD
}

Authors

Institutions
Teppei Yoshioka', Tsutomu Nishida', Masahiko Tsujii', Motohiko Kato' ${ }^{1}$, Yoshito Hayashi' ${ }^{1}$, Masato Komori ${ }^{2}$, Harumasa Yoshihara ${ }^{2}$, Takeshi Nakamura ${ }^{3}$, Satoshi Egawa ${ }^{3}$, Toshiyuki Yoshio ${ }^{4}$, Takuya Yamada ${ }^{4}$, Takamasa Yabuta ${ }^{5}$, Katsumi Yamamoto ${ }^{6}$, Kazuo Kinoshita ${ }^{7}$, Naoki Kawai ${ }^{8}$, Hideharu Ogiyama ${ }^{9}$, Akihiro Nishihara ${ }^{10}$, Tomoki Michida $^{11}$, Hideki lijima ${ }^{1}$, Ayumi Shintani ${ }^{12}$, Tetsuo Takehara ${ }^{1}$

Institutions are listed at the end of article. submitted 28. January 2014 accepted after revision 26. August 2014

\section{Bibliography}

Dol http://dx.doi.org/ 10.1055/s-0034-1390762

Published online: 29.10.2014

Endoscopy International Open 2015; 03: E39-E45

(C) Georg Thieme Verlag KG Stuttgart · New York E-ISSN 2196-9736

\section{Corresponding author}

Tetsuo Takehara

Department of

Gastroenterology and Hepatology

Osaka University Graduate

School of Medicine

Osaka

Japan

Fax: +81-6-68793629

takehara@gh.med.osaka-u.ac.jp
Background and study aims: The number of patients with chronic kidney disease (CKD) is increasing worldwide and gastric cancer sometimes occurs with CKD. However, the safety and feasibility of endoscopic submucosal dissection (ESD) for patients with CKD are not clear. The aim of this study is to clarify the feasibility and safety of gastric ESD for patients with CKD.

Patients and methods: This was a multicenter retrospective cohort study. In total, 144 patients with CKD who underwent gastric ESD between May 2003 and October 2012 were enrolled. The patients were divided into three groups: stage 3 (estimated glomerular filtration rate [eGFR]: $30-$ $59 \mathrm{~mL} / \mathrm{min}$ ), stage 4 (eGFR: $15-29 \mathrm{~mL} / \mathrm{min}$ ), and stage 5 (eGFR: $<15 \mathrm{~mL} / \mathrm{min}$ ) according to the Kidney Disease Improving Global Outcomes Guidelines. The en bloc and curative resection rates and complications were assessed as short-term outcomes. Overall survival was analyzed using Kaplan-Meier methods.

\section{Introduction \\ $\nabla$}

Gastric cancer is the fourth most common cancer and the second most common cause of death from cancer worldwide [1,2]. High-risk areas are Japan, China, Eastern Europe, and certain countries in Latin America owing to the high prevalence of Helicobacter pylori infection in these regions [3]. Early gastric cancer (EGC) is defined as gastric cancer confined to the mucosa or submucosa, irrespective of the presence of regional lymph node metastasis. The prognosis of EGC is good if there is no concomitant lymph node metastasis, with a 5-year gastric cancer-specific survival rate of $99 \%$ [4]. In Japan, $40 \%$ to $50 \%$ of all gastric cancers are EGC, and endoscopic submucosal dissection (ESD) is widely accepted as a local treatment for these lesions because it preserves the whole stomach and postoperative patient
Results: In total, 92 patients were in stage 3 CKD; 23 in stage 4; and 29 in stage 5, including 19 patients in hemodialysis. The en bloc resection rate was $95.8 \%$. Post-ESD bleeding was observed in four patients with stage 5 CKD (13.8\%), three with stage 4 (13.0\%), and one with stage 3 (1.1\%). All bleeding could be controlled by endoscopic hemostasis, but five patients required blood transfusion. Perforation occurred in two patients (6.9\%) with stage $5 \mathrm{CKD}$, none ( $0 \%$ ) with stage 4 , and two (4.3\%) with stage 3.Multivariate Poisson regression analysis revealed CKD stage 4 was a critical factor related to bleeding, whereas diabetes mellitus and CKD stage 5, which largely consist of patients receiving hemodialysis, were not. The median observation period of patients who achieved curative resection was 25.9 months (range 0.8-112.7 months) and the 3year overall survival rate was $92.5 \%$.

Conclusions: Estimated GFR is a significant independent predictive factor of post-ESD bleeding in patients with CKD.

quality of life. ESD has become a general technique because of improved procedures, devices, and patient selection. We recently reported that less invasive gastric ESD is feasible even for elderly patients [5].

The number of patients with chronic kidney disease (CKD) is increasing worldwide. Japanese clinical practice guidelines reported that the CKD frequencies in Japanese adults in 2009 were $0.6 \%$, $1.7 \%, 10.4 \%$, and $0.2 \%$ for stages $1,2,3$, and $4 / 5$, respectively. The total number of patients in stages 3 to 5 was estimated to be approximately 10.97 million [6]. CKD increases in line with advancing age and the number of patients with gastric cancer suffering from CKD will also likely increase.

CKD is generally evaluated by serum creatinine level. Estimated glomerular filtration ratio (eGFR) is calculated by serum creatinine, age, and sex ac- 
cording to the following equation: eGFR $(\mathrm{mL} / \mathrm{min})=194 \times \mathrm{Cr}-$ $1.094 \times$ age $-0.287(\times 0.739$ if female) [7].

Estimated GFR is more useful than using serum creatinine alone. According to the Kidney Disease Improving Global Outcomes (KDIGO) guideline, the risk for cerebrovascular disease in patients with CKD is classified by eGFR and urinary protein [8]. Grade 3a (eGFR: $45-59 \mathrm{~mL} / \mathrm{min}$ ) with proteinuria and more than Grade 3b are at high risk for cerebrovascular disease. Estimated GFR values are now reported by more than $80 \%$ of clinical laboratories in the United States [9], and accurate estimation of GFR is important for detecting and staging CKD, determining drug dosages, and stratifying risks [10].

Surgical intervention is more invasive and more complications occur, such as excessive bleeding related to uremic platelet dysfunction and tissue vulnerability, in patients with CKD than in those without CKD $[11,12]$. For EGC, gastric ESD is less invasive and this makes gastric ESD feasible even for elderly patients. However, the safety and feasibility of gastric ESD for Patients with CKD are not clear. Here we analyzed the complications and prognosis for gastric ESD in patients with CKD.

\section{Patients and methods \\ Participating hospitals}

This study was a multicenter retrospective cohort study from 10 hospitals participating in the Osaka Gut Forum, which comprises one university hospital, five secondary care hospitals, and four tertiary care hospitals ( $\bullet$ Table 1 ). The study was approved by the Osaka University Institutional Review Board (No.13055) and was performed in accordance with the Declaration of Helsinki (2008).

\section{Patients}

In total, 144 patients with CKD who underwent gastric ESD between May 2003 and October 2012 in the 10 hospitals were enrolled. All procedures were performed after obtaining informed consent from the patients. CKD was diagnosed when eGFR was less than $60 \mathrm{~mL} / \mathrm{min}$. For simple use in clinical bedside setting, just eGFR was used for classification of CKD in this study. Patients with CKD were divided into three groups: stage 3: eGFR 30-59 $\mathrm{mL} / \mathrm{min}$, stage 4: eGFR $15-29 \mathrm{~mL} / \mathrm{min}$, and stage 5: eGFR $<15 \mathrm{~mL} /$ min or hemodialysis (HD) according to Japanese practice guidelines for the treatment of CKD [6]. EGC lesion criteria were de-

Table 1 Hospitals participating in this study, and the number and percentage of patients from each hospital

\begin{tabular}{|rlcr|}
\hline & Participating hospital & No. of patients & \multicolumn{1}{c|}{$\%$} \\
\hline 1 & Osaka University Hospital & 73 & 50.7 \\
\hline 2 & Osaka Rosai Hospital & 18 & 12.5 \\
\hline 3 & Kansai Rosai Hospital & 17 & 11.8 \\
\hline 4 & Osaka National Hospital, & 9 & 6.3 \\
\hline & National Hospital Organization & & \\
\hline 5 & Sakai City Hospital & 8 & 5.6 \\
\hline 6 & Toyonaka City Hospital & 7 & 4.9 \\
\hline 7 & Sumitomo Hospital & 5 & 3.5 \\
\hline 8 & Osaka Police Hospital & 3 & 2.1 \\
\hline 9 & Itami Municipal Hospital & 2 & 1.4 \\
\hline 10 & Minoh City Hospital & 2 & 1.4 \\
\hline & Total & $\mathbf{1 4 4}$ & $\mathbf{1 0 0}$ \\
\hline
\end{tabular}

fined according to the Japanese Gastric Cancer Association guidelines [4].

\section{ESD procedure}

ESD was performed by conventional endoscopy (GIF-Q260J, GIFH260Z; Olympus, Tokyo, Japan) at each institute. All cases were performed by operators who had used gastric ESD or its certain supervision in more than 50 cases. Details of the procedure, such as saline or hyaluronic acid injection mixed with or without epinephrine, and use of an IT knife (Olympus, Tokyo, Japan), Flush Knife (Fujifilm, Tokyo, Japan) or others were decided by the physician and institution. When we suspected complications such as perforation or bleeding, a computed tomography (CT) or emergency esophagogastroduodenoscopy (EGD) was performed based on the judgment of the attending physician.

\section{Management of HD, anticoagulants, and antiplatelet agents}

There was no peritoneal dialysis in this study. Most of the patients were receiving hemodialysis three times per a week in their satellite hospital. Patients with HD were usually admitted 2 days before the date of ESD operation, and they received HD the day before ESD. We usually used nafamostat instead of heparin to prevent the residual anticoagulant effect in HD before the ESD procedure.

In this study, antithrombogenic agents included anticoagulants such as warfarin, and antiplatelet agents such as aspirin, ticlopidine, beraprost, cilostazol, eicosapentaenoic acid ethyl ester, and clopidgrel. If a patient was taking antithrombogenic agents, each drug holiday before and after ESD was basically determined according to the guidelines of the Japan Gastroenterological Endoscopy Society (JGES) [13]. The JGES recommendation with regard to drug holidays for high-risk procedures are as follows: warfarin 3 to 4 days, aspirin 3 days, ticlopidine 5 days, and aspirin-ticlopidine combination therapy 7 days. Unfractionated heparin sodium was used for heparin bridge therapy. Continuous administration of heparin was initiated in the hospital. Patients stopped taking warfarin or antiplatelet agents several days before the procedure according to the guidelines. The prothrombin time-international ratio (PT-INR) for warfarin and the activated partial thromboplastin time (APTT) for heparin were monitored to check the anticoagulant effect. The dose of heparin was controlled to keep the APTT at around 60 seconds (1.5-2 times the upper normal limit) at the recommendation of cardiologists. Heparin was stopped 4 to 6 hours before ESD, and ESD was performed after the disappearance of the anticoagulant effect. After ESD, administration of heparin was resumed as soon as possible. Although a decision to restart depended on both the necessity for anticoagulation and the bleeding tendency of the individual during the procedure, most of the patients were restarted on heparin after clinical examination, a blood test to check anemia and second-look endoscopy on postoperative day 1 . Warfarin was basically resumed on postoperative day 1 .

\section{Outcomes}

We set major complications of gastric ESD as a primary end point. A major complication was defined as post-ESD bleeding and perforation. Post-ESD bleeding was defined as the need for emergency endoscopic hemostasis or a fall in the hemoglobin level $>2 \mathrm{~g}$ / $\mathrm{dL}$ below the preoperative level. Perforation was diagnosed endoscopically during ESD or by the observation of free air in post-ESD plain radiography or CT. As short-term outcomes, the en bloc and 
Table 2 Clinical characteristics of patients with chronic kidney disease (CKD) and early gastric cancer (EGC)

\begin{tabular}{|c|c|c|c|c|c|}
\hline & Total & Stage 3 & Stage 4 & Stage 5 & $P$-value \\
\hline Number, $\mathrm{n}$ & 144 & 92 & 23 & 29 & - \\
\hline Age & $73.8 \pm 7.9$ & $73.6 \pm 7.5$ & $73.8 \pm 10.1$ & $74.9 \pm 7.6$ & 0.592 \\
\hline Sex, male (\%) & $113(78.5)$ & $75(81.5)$ & $15(65.2)$ & $23(79.3)$ & 0.228 \\
\hline Body height, $\mathrm{cm}$ & $160.3 \pm 9.5$ & $161.6 \pm 9.1$ & $157.0 \pm 9.3$ & $159.4 \pm 10.8$ & 0.063 \\
\hline Body weight, kg & $59.0 \pm 12.5$ & $60.5 \pm 12.8$ & $58.3 \pm 12.5$ & $56.2 \pm 10.6$ & 0.248 \\
\hline eGFR, $\mathrm{mL} / \mathrm{min}$ & $36.4 \pm 18.3$ & $48.7 \pm 7.7$ & $23.6 \pm 7.1$ & $7.5 \pm 2.3$ & $<0.001$ \\
\hline $\mathrm{Cr}, \mathrm{mg} / \mathrm{dL}$ & $2.51 \pm 2.84$ & $1.12 \pm 0.21$ & $2.18 \pm 1.26$ & $7.23 \pm 3.14$ & $<0.001$ \\
\hline $\mathrm{Hb}, \mathrm{g} / \mathrm{dL}$ & $12.0 \pm 1.9$ & $12.8 \pm 1.7$ & $10.7 \pm 1.5$ & $10.4 \pm 1.4$ & $<0.001$ \\
\hline $\mathrm{PLT}, 10^{4} / \mu \mathrm{L}$ & $19.5 \pm 5.8$ & $19.7 \pm 5.5$ & $19.9 \pm 6.0$ & $18.8 \pm 7.3$ & 0.453 \\
\hline Hemodialysis, n (\%) & $19(13.2)$ & $0(0)$ & $0(0)$ & $19(65.5)$ & $<0.001$ \\
\hline Diabetes mellitus, $n(\%)$ & $40(27.8)$ & $17(18.5)$ & $7(30.4)$ & $16(55.2)$ & $<0.001$ \\
\hline Antithrombogenic agents, $\mathrm{n}(\%)$ & $43(29.9)$ & $19(20.7)$ & $9(39.1)$ & $15(51.7)$ & 0.004 \\
\hline Heparin replacement therapy, n (\%) & $7(4.9)$ & $4(4.3)$ & $2(8.7)$ & $1(3.4)$ & 0.638 \\
\hline
\end{tabular}

eGFR, estimated glomerular filtration rate; PLT, platelet count.

Stages from Kidney Disease Improving Global Outcomes Guidelines: stage 3, eGFR: $30-59 \mathrm{~mL} / \mathrm{min}$; stage 4, eGFR: 15-29mL/min; stage 5, eGFR:<15 mL/min.

curative resection rates and incidence of blood transfusion were also assessed. En bloc resection was defined as resection in a single piece of tissue. Curative resection was defined when the resected specimen satisfied en bloc resection, negative horizontal and vertical margins (HM0, VM0), no invasion into the lymph duct and venous duct (ly0, v0), and following conditions (a) to (d) according to the Japanese Gastric Cancer Association [4].

a) any tumor size, histologically of differentiated-type, pT1a, no ulcerative findings ( $\mathrm{UL}(-))$

b) tumor size $\leq 3 \mathrm{~cm}$, histologically of differentiated-type, pT1a, ulcerative findings $(\mathrm{UL}(+))$

c) tumor size $\leq 2 \mathrm{~cm}$, histologically of undifferentiated-type, pT1a, UL $(-)$

d) tumor size $\leq 3 \mathrm{~cm}$, histologically of differentiated-type, pT1b

(SM1, <500 $\mu \mathrm{m}$ from muscularis mucosae)

As middle- to long-term outcomes, we analyzed the prognosis of patients with CKD after gastric ESD.

\section{Statistics}

A one-sided $P$-value of less than 0.05 was considered statistically significant. When we compared the three CKD categories, we used the Kruskal-Wallis test for continuous variables and Fisher's exact test for nominal variables. Because the number of bleeding events was small ( $\mathrm{n}=8$ total), a conventional analysis with logistic regression may yield an unstable estimate, thus we used Poisson regressions for both univariate and multivariate analyses to assess the effect of CKD categories on bleeding. With Poisson regression, Huber-White sandwich estimators were used to more accurately estimate variance-covariance to avoid overdispersion which could occur if a conventional method without such robust estimators was used instead. Receiver Operating Characteristic (ROC) curve analysis was used to determine the cutoff value of eGFR for predicting bleeding. As middle- to longterm outcomes, overall survival was analyzed using Kaplan - Meier methods. Statistical analyses were performed using JMP software (ver. 10.0.2, SAS Institute Inc., Cary, NC, United States).

\section{Results}

\section{$\nabla$}

Patient characteristics

Patient characteristics are shown in Table 2. Mean patient age was $73.8 \pm 7.9$ years, $78.5 \%$ were men. There were 92 patients in stage 3, 23 in stage 4 , and 29 in stage 5 . There were 19 patients who required HD (13.2\%), 40 patients had diabetes mellitus (DM) (27.8\%), 43 patients used antithrombogenic agents (29.9 $\%)$, and seven patients underwent ESD with heparin replacement (HR) (4.9\%). There was no statistically significant difference among the three groups in terms of age, sex, body height, body weight, or platelet count. The frequencies of patients with DM, $\mathrm{HD}$, or using antithrombogenic agents were inversely correlated with eGFR, but not HR. Hemoglobin levels were lower in patients with CKD stage 4 and 5 owing to renal anemia. There were no statistically significant differences in the backgrounds of EGC among the three groups ( Table 3 ).

\section{Short-term outcome}

The en bloc resection rate was $95.8 \%$ and the curative resection rate was $86.1 \%$. Perforation occurred in four, zero, and two patients in stage 3,4 , and 5 , respectively ( $4.3 \%, 0 \%$, and $6.9 \%$ ). There were no statistically significant differences among the three groups in terms of en bloc resection rate, curative resection rate, or perforation rate ( Table 4). All patients with perforations were controlled by conservative therapy, such as clipping, intravenous administration, antibiotics, and proton pump inhibitors, and no one required surgery related to peritonitis.

Post-ESD bleeding was observed in $1.1 \%$ of patients in stage 3 ( 1 / 92), $13.0 \%$ in stage $4(3 / 23)$, and $13.8 \%$ in stage 5 (4/29). All bleeding was controlled by endoscopic hemostasis, but five patients required blood transfusion (3.5\%). In univariate Poisson regression analysis by CKD stage, HD, DM, use of antithrombogenic agent and HR, critical factors related to bleeding were CKD stage and HD. DM, use of anticoagulants, and HR were not critical factors related to bleeding ( Table 5). Multivariate Poisson regression analyses were performed among DM, CKD stage 3, 4, and 5. HD was not included because patients receiving HD largely overlapped CKD stage 5 where 19 of 29 stage 5 patients had HD. In multivariate Poisson regression analysis, CKD stage 4 was statistically significantly different although stage 5 did not achieve statistical significance (risk ratio 11.4 [1.1-116.6], $P=0.040$ in patients with stage 4 and 11.0 [0.874-137.3], $P=0.064$ in patients 


\begin{tabular}{|c|c|c|c|c|c|}
\hline & Total & $\begin{array}{l}\text { Stage } 3 \\
(n=92)\end{array}$ & $\begin{array}{l}\text { Stage } 4 \\
(n=23)\end{array}$ & $\begin{array}{l}\text { Stage } 5 \\
(n=29)\end{array}$ & $P$-value \\
\hline Tumor size (mm) & $17.2 \pm 11.0$ & $17.7 \pm 11.1$ & $14.7 \pm 11.0$ & $17.8 \pm 11.0$ & 0.463 \\
\hline \multicolumn{5}{|l|}{ Tumor location } & 0.358 \\
\hline Upper, n & 13 & 11 & 1 & 1 & - \\
\hline Middle, $\mathrm{n}$ & 58 & 39 & 11 & 8 & - \\
\hline Lower, n & 67 & 39 & 10 & 18 & - \\
\hline Other, $\mathrm{n}$ & 6 & 3 & 1 & 2 & - \\
\hline \multicolumn{5}{|l|}{ Macroscopic type } & 0.867 \\
\hline I or Ila, n & 57 & 34 & 9 & 14 & - \\
\hline IIc or Ila + IIc, n & 70 & 46 & 12 & 12 & - \\
\hline Other, $\mathrm{n}$ & 17 & 12 & 2 & 3 & - \\
\hline \multicolumn{5}{|l|}{ Histologic type } & 0.893 \\
\hline Intestinal, n & 134 & 86 & 21 & 27 & - \\
\hline Diffuse, $n$ & 10 & 6 & 2 & 2 & - \\
\hline \multicolumn{5}{|l|}{ Invasive depth } & 0.518 \\
\hline$M, n$ & 131 & 82 & 21 & 28 & - \\
\hline SM1, n & 7 & 5 & 2 & 0 & - \\
\hline$>\mathrm{SM} 2, \mathrm{n}$ & 6 & 5 & 0 & 1 & - \\
\hline Ulceration, n (\%) & $19(13.0)$ & $16(17.0)$ & $1(4.3)$ & $2(7.4)$ & 0.185 \\
\hline \multicolumn{5}{|c|}{ Guideline classification [4] } & 0.572 \\
\hline Intra, n & 100 & 61 & 17 & 22 & - \\
\hline Expand, $n$ & 34 & 22 & 6 & 6 & - \\
\hline Extra, $n$ & 10 & 9 & 0 & 1 & - \\
\hline
\end{tabular}

M, tumor remains in mucosa; SM1, tumor invasion to submucosa $(<500 \mu \mathrm{m})$; SM2; tumor invasion to submucosa $(\geq 500 \mu \mathrm{m})$; Intra, tumor $<2 \mathrm{~cm}$, differentiated type, without ulcerative findings (UL(-)); M, Expand: tumor satisfied expansion criteria of Japanese Gastric Cancer Association (JGCA); Extra: tumor did not satisfy expansion criteria of JGCA [4]. Stages from Kidney Disease Improving Global Outcomes Guidelines: stage 3, eGFR: 30 - 59 mL/min; stage 4, eGFR: 15-29mL/min; stage 5, eGFR:<15 mL/min.

\begin{tabular}{|c|c|c|c|c|c|}
\hline CKD Stage & $\begin{array}{l}\text { Total } \\
(n=144)\end{array}$ & $\begin{array}{l}\text { Stage } 3 \\
(n=92)\end{array}$ & $\begin{array}{l}\text { Stage } 4 \\
(n=23)\end{array}$ & $\begin{array}{l}\text { Stage } 5 \\
(\mathrm{n}=29)\end{array}$ & $P$-value \\
\hline En bloc resection, $\mathrm{N}(\%)$ & $138(95.8)$ & $86(93.5)$ & $23(100)$ & $29(100)$ & 0.314 \\
\hline Curative resection, $\mathrm{N}(\%)$ & $124(86.1)$ & $77(83.7)$ & $22(95.6)$ & $25(86.2)$ & 0.387 \\
\hline Perforation, N (\%) & $6(4.2)$ & $4(4.3)$ & $0(0)$ & $2(6.9)$ & 0.600 \\
\hline Bleeding, $\mathrm{N}(\%)$ & $8(5.6)$ & $1(1.1)$ & $3(13.0)$ & $4(13.8)^{1}$ & 0.004 \\
\hline Transfusion, N (\%) & $5(3.5)$ & $0(0)$ & $3(13.0)^{2}$ & $2(6.9)$ & 0.004 \\
\hline
\end{tabular}

$1 P=0.012$ vs Stage 3 by Fisher's exact analysis with Bonferroni adjustment

${ }^{2} P=0.007$ vs Stage 3 by Fisher's exact analysis with Bonferroni adjustment

with stage 5) ( Table 6). ROC analysis of the cutoff value of eGFR for predicting post-ESD bleeding was carried out and the area under the ROC curve (AUC) was 0.80 (95\% Confidence Interval: $0.71-0.89$ ) ( Fig. 1). When we set a cutoff value in eGFR of $27.3 \mathrm{~mL} / \mathrm{min}$, sensitivity and specificity were the highest and their percentages were $87.5 \%$ and $70.6 \%$, respectively. There was no death related to the ESD procedure in all 144 patients.

\section{Middle- to long-term outcome}

Of these 144 patients, 20 did not achieve curative resection (13.9 $\%$ ) and an additional surgical operation was performed in 14 patients (9.7\%) ( Fig. 2). The reasons for no curative resection are shown in Table 7. In those 14 patients operated, no patients died of gastric cancer, however, one patient died of hepatic failure 51.5 months after ESD. The remaining six patients who did not achieve curative resection were monitored. The reasons for monitoring were detection of another malignancy, the general condition of the patient or refusal to undergo additional surgical treatment because of the low risk of residual malignancy. The median monitoring period was 21.1 months (range 2.7-78.9 months). There was no disease-specific death, however, one patient died from another malignancy.

Another 124 patients achieved curative resection and their median observation period was 25.9 months (range 0.8-112.7 months). No disease-specific death occurred, however, eight patients died from other reasons. Of these eight, three died because of other cancers, two died from infection and two from CKD exacerbation, and the other death was the result of heart failure. The Kaplan-Meier curve for survival of post-ESD patients who achieved curative resection is shown in $\bullet$ Fig. 3, and the 3-year overall survival rate was $92.5 \%$.

\section{Discussion}

CKD is increasingly recognized as a global public health problem. It can be detected using simple laboratory tests, and is becoming a common disease in Japan. The number of patients with CKD in Japan is estimated to be approximately 13.3 million, comprising $13 \%$ of the Japanese population. In general, it is often complicated 


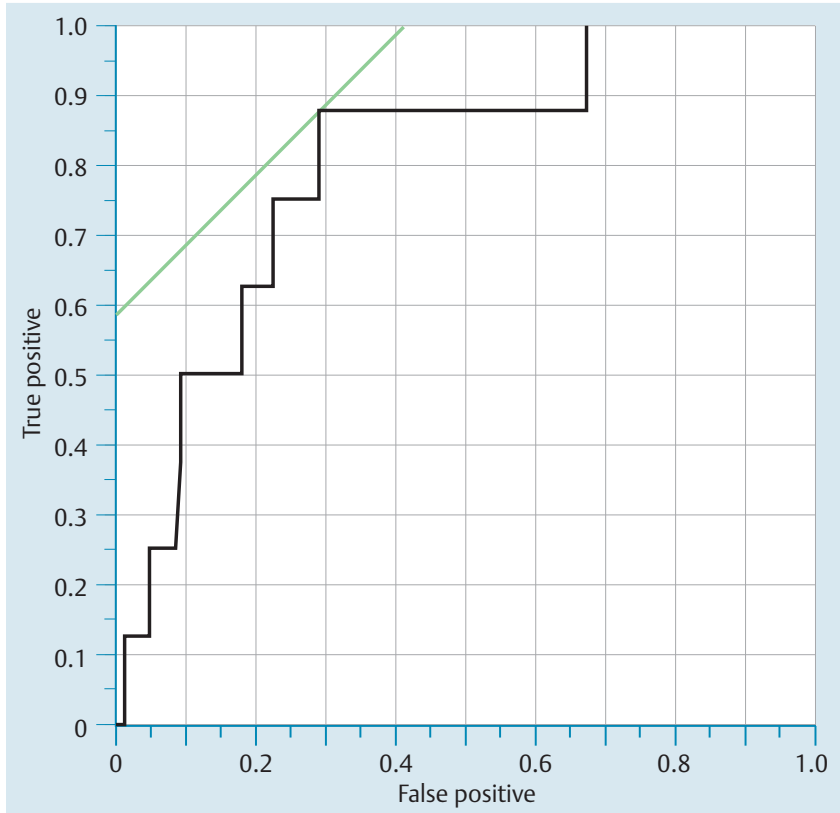

Fig. 1 Receiver-operating characteristic (ROC) curves predicted bleeding after ESD in patients with chronic kidney disease (CKD).

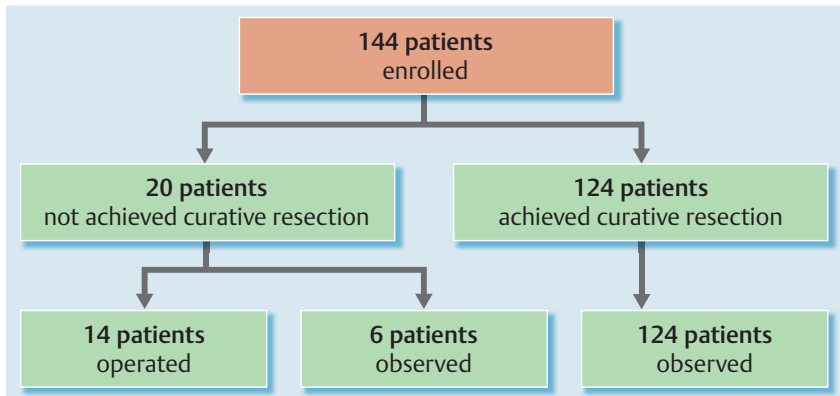

Fig. 2 Schema of treatment plan after ESD.

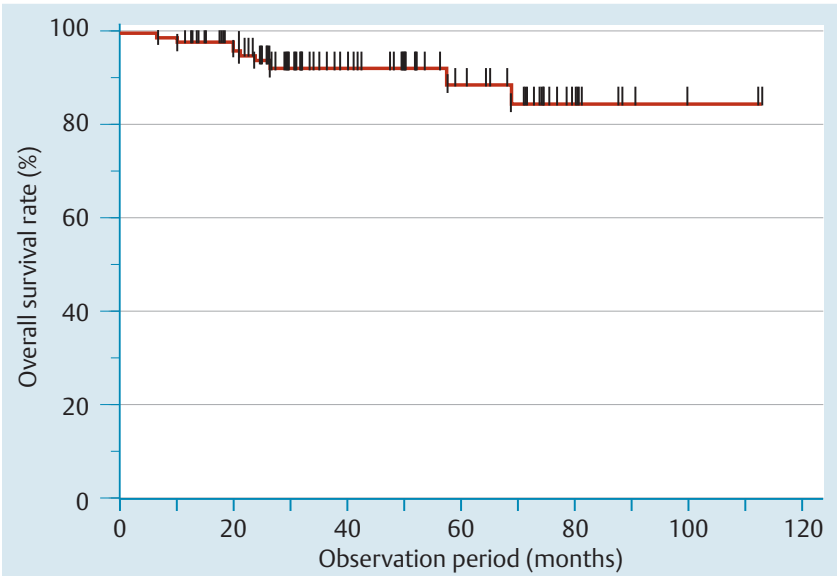

Fig. 3 Cumulative overall survival curve of patients who achieved curative resection. There was no disease specific death, however, eight patients died of other reasons. The 3 -year overall survival rate was $92.5 \%$.
Table 5 Risk factors for post-ESD bleeding by univariate Poisson regression analysis

\begin{tabular}{|c|c|c|c|}
\hline Factors & & $\begin{array}{l}\text { Relative Risk [95\% } \\
\mathrm{Cl}]\end{array}$ & $P$-value \\
\hline \multirow[t]{3}{*}{ CKD stage } & 3 & 1 & - \\
\hline & 4 & $12.0[1.3-110.1]$ & 0.028 \\
\hline & 5 & $12.7[1.5-109.1]$ & 0.021 \\
\hline \multirow[t]{2}{*}{ Hemodialysis } & No & 1 & \multirow{2}{*}{0.004} \\
\hline & Yes & $6.6[1.8-24.1]$ & \\
\hline \multirow{2}{*}{ Diabetes mellitus } & No & 1 & \multirow[t]{2}{*}{0.161} \\
\hline & Yes & $2.6[0.7-9.9]$ & \\
\hline \multirow[t]{2}{*}{ Antithrombogenic agents } & No & 1 & \multirow[t]{2}{*}{0.211} \\
\hline & Yes & $2.3[0.6-9.0]$ & \\
\hline \multirow{2}{*}{$\begin{array}{l}\text { Heparin replacement } \\
\text { therapy }\end{array}$} & No & 1 & \multirow[t]{2}{*}{0.378} \\
\hline & Yes & $2.8[0.4-19.7]$ & \\
\hline
\end{tabular}

Stages from Kidney Disease Improving Global Outcomes Guidelines: stage 3, eGFR: $30-59 \mathrm{~mL} / \mathrm{min}$; stage 4, eGFR: $15-29 \mathrm{~mL} / \mathrm{min}$; stage 5 , eGFR: $<15 \mathrm{~mL} / \mathrm{min}$.

Table 6 Adjusted Odds ratio assessing the effect of CKD-stage bleeding ${ }^{1}$ by multivariate logistic Poisson analysis

\begin{tabular}{|llll|} 
Factor & $\begin{array}{l}\text { Stage 3 } \\
\text { (Reference) }\end{array}$ & $\begin{array}{l}\text { Stage } 4 \\
\text { RR }[95 \% \mathrm{CI}], \\
\text { P-value }\end{array}$ & $\begin{array}{l}\text { Stage } 5^{2} \\
\text { RR [95\%Cl], } \\
\text { P-value }\end{array}$ \\
\hline Bleeding & 1 & $\begin{array}{l}11.4[1.1-116.6], \\
0.040\end{array}$ & $\begin{array}{l}11.0[0.9-137.3] \\
0.064\end{array}$ \\
\hline
\end{tabular}

1 Adjusted for diabetes mellitus (DM).

2 Including $\mathrm{n}=19$ dialysis patients.

Table 7 Reasons for no curative resection and incidence of additional operations

\begin{tabular}{|lll|}
\hline Reason for no curative resection & $\begin{array}{l}\text { Number } \\
\text { of patients }\end{array}$ & $\begin{array}{l}\text { Additional } \\
\text { surgical } \\
\text { operation }\end{array}$ \\
\hline Positive margin & 9 & 6 \\
\hline Invasion $\geq$ SM2 & 5 & 4 \\
\hline Invasion of lymph duct & 3 & 2 \\
\hline SM1 and (size $>30$ mm or UL(+)) & 2 & 2 \\
\hline $\begin{array}{l}\text { Undifferentiated-type and size } \\
>20 \text { mm }\end{array}$ & 1 & 0 \\
\hline Total & $20(13.9 \%)$ & $14(9.7 \%)$ \\
\hline
\end{tabular}

SM1, tumor invasion to submucosa ( $<500 \mu \mathrm{m})$; SM2; tumor invasion to submucosa $(\geq 500 \mu \mathrm{m})$; $\mathrm{UL}(+)$, with ulcerative findings.

by coexisting diseases owing to bleeding tendencies, arteriosclerosis, and immunologic changes. Thus, patients with CKD are considered to be a high-risk group for surgery-related complications [14].

Surgical resection is a radical treatment for patients with EGC. If well-differentiated to moderately-differentiated lesions are limited to the mucosal layer, endoscopic resection is widely accepted as a local treatment because it preserves the entire stomach as well as the patient's quality of life postoperatively. In particular, ESD achieves a secure resection with an acceptable complication rate and the indications for ESD are expanding. Based on a multicenter study, we recently reported that ESD is a feasible method for treating EGC [5]. When the gastric lesions are considered to be an indication for ESD, tumor factors, as well as general status, such as age, performance status, and other underlying diseases, must be considered to determine the feasibility of ESD. CKD is be- 
coming a big issue in the consideration of the indications for gastric ESD. However, there have been few reports to date with regard to the short-term outcome of gastric ESD in cases of CKD, as well as the long-term survival. In this study, we evaluated the feasibility, the risk factors for ESD-related complications, and mid-term survival in patients with CKD in a multicenter survey including municipal hospitals.

Generally, gastrointestinal bleeding in patients with CKD is reportedly increased as a result not only of gastroduodenal peptic ulcers, but also non-peptic and non-variceal lesions [15]. This is suspected to be to the result of dysfunctional hemostasis combined with mucosal abnormalities and hypergastrinemia. The possible mechanisms of bleeding in patients with CKD may be uremic platelet dysfunction, platelet-vessel wall interaction, or abnormalities in blood coagulation [16,17], and other factors, such as medications, and comorbid conditions. In particular, HD is well known to be a risk factor for bleeding [18], especially during the ESD procedure $[19,20]$. In this study, HD was also a risk factor for bleeding in the univariate analysis. In multivariate analysis, however, the risk ratio of bleeding in patients with stage 4 CKD was higher than in patients with stage 5 CKD, which included 19 patients on HD. This may reveal the important finding that eGFR is an independent risk factor for bleeding after gastric ESD regardless of whether a patient received HD or not. ROC curve analysis also showed that the best cut-off value for eGFR to predict bleeding was $27.3 \mathrm{~mL} / \mathrm{min}$, which is considered to be a reasonable risk for performing ESD in patients with CKD stage $4 / 5$ (eGFR $\leq 29 \mathrm{~mL} / \mathrm{min})$. We also demonstrated that patients with CKD had the highest percentage of transfusions after gastric ESD. Soyoral et al. reported that skin bleeding-time after the first HD was shorter compared to the pre-dialysis value, because HD improves uremia and platelet function [21]. Winkelmayer et al. reported that CKD was associated with the risk for postoperative bleeding in patients undergoing coronary artery bypass grafting surgery, not only at more advanced stages, but probably also at relatively mild levels of renal impairment [22]. These reports may support our findings. On the other hand, Numata et al. reported that the post-ESD bleeding rate was $33 \%$ in patients undergoing HD, whereas it was only $9 \%$ in non-HD patients, and concluded that the cause of bleeding was associated with other comorbidities, such as the use of anticoagulants in HD, but did not depend on the eGFR [23]. This was a retrospective study of 79 patients with CKD who underwent ESD in a single high-volume center and focused on HD, not eGFR. In the present study, we evaluated 144 patients with CKD, focusing not only on HD but also on eGFR in a multicenter survey including municipal hospitals where many patients with CKD were among the patients undergoing ESD. Kwon et al. also reported a single center retrospective study that compared 17 patients with CKD to 894 control patients who received gastric ESD [24]. They reported no significant difference in en bloc resection and perforation rates between patients with CKD and controls, but bleeding tendencies were observed in patients with CKD.

Goto et al. also reported 10 case series of ESD in patients with CKD and undergoing HD [25]. One of them had a late perforation after rectal ESD and required emergency surgery. Therefore, they concluded that caution should be exercised in patients with CKD because they have less reserved capacity. Not including rectal ESD in our study, however, perforation rates were not significantly different among the three groups and no emergency surgery related to ESD was required. Generally, patients with CKD are known to have particularly impaired wound healing abilities
$[26,27]$ and a high risk of atherosclerosis with vascular calcification that might easily lead to perforation. In the present study, we showed that the en bloc resection rate was $95.8 \%$, which means that gastric ESD was technically feasible even in patients with severe CKD. Based on these results, special care should be taken in patients with stage 4 or 5 CKD to minimize the risk of bleeding when undergoing ESD. Performing second look endoscopy is controversial, but Choi et al. reported that selective second look endoscopy is useful in patients with a high risk of bleeding [28]. With regard to middle- to long-term prognosis, we reported that the 3-year overall survival rate and cause-specific survival rates after gastric ESD for EGC within guideline criteria were $96.8 \%$ and $100 \%$, respectively [29]. There was no cause-specific death in the present study, but overall survival was $92.5 \%$ for 3 years. This was lower than in our historical data [29], however, there were no independent predictors, including HD and CKD stage for the poor prognosis of patients with CKD and with EGC (data not shown). In fact, the prognosis of general HD patients is poor, and the mortality rate of general HD patients is reported to be $\sim 60.3 \%$ for 5 years because of complications such as atherosclerosis and other malignancies caused by immune dysfunction. Therefore, the natural course of CKD should be taken into account when determining the indications for gastric ESD because severe bleeding events affect the survival of patients with CKD but the doubling time of EGC is reported to range from 1.6 to 9.5 years [30]. Fortunately, there were no treatment-related deaths in our study, but bleeding is reported to cause ESD related-death in patients with CKD [23] although, in general, ESD is safe for EGC. There were several limitations in this study owing to the nature of a multicenter, retrospective study. First, the biggest issue of this study is that the parameter of post-ESD bleeding did not reach the recommended size for the cohort. Our study population, 144 patients with CKD, was larger compared to previously published reports, however, not reaching 10 events of post-ESD bleeding gave this study limited power, especially in multivariate analysis. Similarly, we could not clarify other factors such as HR therapy, use of antithrombogenic agents, and DM, owing to the limitations of sample size.

Second, bias of institution is also a problem and about half of our population was from Osaka University. This is because high risk patients such as severe CKD tended to be sent from municipal or city hospitals to high volume centers. Some participating hospitals contributed only two to five cases, however, there was no statistically significant difference in incidence of major complications, such as post-ESD bleeding or perforation, between the high volume centers and other hospitals, when we defined high volume centers as the top three institutions (Osaka University, Osaka Rosai Hospital, and Kansai Rosai Hospital). In addition, we did not unify parameters such as ESD methods, devices, method of observation, and so on, because this was a retrospective cohort. In conclusion, gastric ESD for patients with CKD is technically feasible, even in patients undergoing HD. Estimated GFR is a more significant independent factor for predicting post-ESD bleeding than HD in patients with CKD.

$\mathrm{RR}$, risk ratio.

Stages from Kidney Disease Improving Global Outcomes Guidelines: stage 3, eGFR: $30-59 \mathrm{~mL} / \mathrm{min}$; stage 4, eGFR: $15-29 \mathrm{~mL} /$ min; stage 5 , eGFR: $<15 \mathrm{~mL} / \mathrm{min}$.

\section{Competing interests: None}


Institutions

${ }^{1}$ Department of Gastroenterology and Hepatology, Osaka University Graduate School of Medicine, Suita, Japan

${ }^{2}$ Department of Gastroenterology, Osaka Rosai Hospital, Sakai, Japan

${ }^{3}$ Department of Gastroenterology, Kansai Rosai Hospital, Amagasaki, Japan

${ }^{4}$ Department of Gastroenterology, Osaka National Hospital, National Hospital Organization, Osaka, Japan

${ }^{5}$ Department of Gastroenterology, Sakai City Hospital, Sakai, Japan

${ }^{6}$ Department of Gastroenterology, Toyonaka Municipal Hospital, Toyonaka, Japan

7 Department of Gastroenterology, Sumitomo Hospital, Osaka, Japan

${ }^{8}$ Department of Gastroenterology, Osaka Police Hospital, Osaka, Japan

${ }^{9}$ Department of Gastroenterology, Itami City Hospital, Itami, Japan

${ }^{10}$ Department of Gastroenterology, Minoh City Hospital, Minoh, Japan

${ }^{11}$ Department of Gastroenterology, Osaka Kosei-Nenkin Hospital, Osaka, Japan

${ }^{12}$ Department of Clinical Epidermiology, Osaka University Graduate School of Medicine, Suita, Japan

\section{Acknowledgments}

\section{$\nabla$}

Study investigators: Tomofumi Akasaka, Takuya Inoue, Yoshiki Tsujii, Akira Maekawa (Osaka University Hospital); Masako Sato, Shunsuke Yamamoto, Motohiro Hirao, Shizuyo Nakamoto (Osaka Rosai Hospital); Akinori Shimayoshi, Akira Doi, Shouichi Yoshimizu (Kansai Rosai Hospital); Tetsuya Iwasaki (Osaka National Hospital, National Hospital Organization); Shinji Kitamura (Sakai City Hospital).

\section{References}

1 Crew KD, Neugut AI. Epidemiology of upper gastrointestinal malignancies. Semin Oncol 2004; 31: 450-464

2 Crew KD, Neugut AI. Epidemiology of gastric cancer. World J Gastroenterol 2006; 12: 354-362

3 Fock KM, Talley N, Moayyedi P et al. Asia-Pacific consensus guidelines on gastric cancer prevention. J Gastroenterol Hepatol 2008; 23: 351 365

4 Japanese Gastric Cancer Association. Japanese gastric cancer treatment guidelines 2010 (ver. 3). Gastric Cancer 2011; 14: 113-123

5 Akasaka T, Nishida T, Tsutsui $S$ et al. Short-term outcomes of endoscopic submucosal dissection (ESD) for early gastric neoplasm: multicenter survey by Osaka University ESD study group. Dig Endosc 2011; 23: $73-77$

6 Japanese Society of Nephrology. Evidence-based practice guideline for the treatment of CKD. Clin Exp Nephrol 2009; 13: 537-566

7 Matsuo S, Imai E, Horio $M$ et al. Revised equations for estimated GFR from serum creatinine in Japan. Am J Kidney Dis 2009; 53: 982 - 992

8 Levey AS, de Jong PE, Coresh J et al. The definition, classification, and prognosis of chronic kidney disease: a KDIGO Controversies Conference report. Kidney Int 2011; 80: 17-28

9 Miller WG. Estimating glomerular filtration rate [Editorial]. Clin Chem Lab Med 2009; 47: 1017-1019

10 Stevens LA, Coresh J, Greene T et al. Assessing kidney function measured and estimated glomerular filtration rate. N Engl J Med 2006; 354: $2473-2483$
11 Yasuda K, Tahara K, Kume M et al. Risk factors for morbidity and mortality following abdominal surgery in patients on maintenance hemodialysis. Hepatogastroenterology 2007; 54: 2282 -2284

12 Wind P, Douard R, Rouzier R et al. Abdominal surgery in chronic hemodialysis patients. Am Surg 1999; 65: 347-351

13 Ogoshi K, Kaneko E, Tada $M$ et al. The management of anticoagulation and antiplatelet therapy for endoscopic procedures. Gastroenterol Endosc 2005; 47: 2691 - 2695

14 Cherng YG, Liao CC, Chen TH et al. Are non-cardiac surgeries safe for dialysis patients? - A population-based retrospective cohort study PLoS One 2013; 8: e58942

15 Luo JC, Leu HB, Hou MC et al. Nonpeptic ulcer, nonvariceal gastrointestinal bleeding in hemodialysis patients. Am J Med 2013; 126: 264. e25-e32

16 Kaw D, Malhotra D. Platelet dysfunction and end-stage renal disease. Semin Dial 2006; 19: 317-322

17 Hörl WH. Thrombocytopathy and blood complications in uremia. Wien Klin Wochenschr 2006; 118: 134 - 150

18 Luo JC, Leu HB, Huang KW et al. Incidence of bleeding from gastroduodenal ulcers in patients with end-stage renal disease receiving hemodialysis. CMAJ 2011; 183: E1345-1351

19 Higashiyama M, Oka S, Tanaka $S$ et al. Risk factors for bleeding after endoscopic submucosal dissection of gastric epithelial neoplasm. Dig Endosc 2011; 23: 290-295

20 Toyokawa T, Inaba T, Omote $S$ et al. Risk factors for perforation and delayed bleeding associated with endoscopic submucosal dissection for early gastric neoplasms: analysis of 1123 lesions. J Gastroenterol Hepatol 2012; 27: 907-912

21 Soyoral YU, Demir C, Begenik $H$ et al. Skin bleeding time for the evaluation of uremic platelet dysfunction and effect of dialysis. Clin Appl Thromb Hemost 2012; 18: 185 - 188

22 Winkelmayer WC, Levin R, Avorn J. Chronic kidney disease as a risk factor for bleeding complications after coronary artery bypass surgery. Am J Kidney Dis 2003; 41: 84-89

23 Numata N, Oka S, Tanaka $S$ et al. Clinical outcomes of endoscopic submucosal dissection for early gastric cancer in patients with chronic kidney disease. J Gastroenterol Hepatol 2013; 28: 1632-1637

24 Kwon YL, Kim ES, Lee KI et al. Endoscopic treatments of gastric mucosal lesions are not riskier in patients with chronic renal failure or liver cirrhosis. Surg Endosc 2011; 25: 1994 - 1999

25 Goto O, Fujishiro M, Kodashima $S$ et al. Feasibility of endoscopic submucosal dissection for patients with chronic renal failure on hemodialysis. Dig Endosc 2010; 22: 45-48

26 Nayman J. Effect of renal failure on wound healing in dogs. Response to hemodialysis following uremia induced by uranium nitrate. Ann Surg 1966; 164: $227-235$

27 Cheung AH, Wong LM. Surgical infections in patients with chronic renal failure. Infect Dis Clin North Am 2001; 15: 775 - 796

28 Choi CW, Kim HW, Kang DH et al. Clinical outcomes of second-look endoscopy after gastric endoscopic submucosal dissection: predictive factors with high risks of bleeding. Surg Endosc 2014; 28: 2213-2220

29 Kato $M$, Nishida T, Yamamoto $K$ et al. Scheduled endoscopic surveillance controls secondary cancer after curative endoscopic resection for early gastric cancer: a multicentre retrospective cohort study by Osaka University ESD study group. Gut 2013; 62: 1425 - 1432

30 Kohli Y, Kawai K, Fujita S. Analytical studies on growth of human gastric cancer. J Clin Gastroenterol 1981; 3: 129-133 